\title{
MISCELLANEA
}

\section{A Simple Micromethod for the Determination of Lead in Small Amounts of Blood*}

\author{
P. E. CORNISH and D. O. SHIELS \\ From the Industrial Hygiene Division of the \\ Department of Health, Victoria, Australia
}

In lead poisoning the determination of the concentration of lead in the blood is a useful aid in diagnosis and also in the supervision of treatment. For clinical purposes, an extremely accurate result is not necessary. It may be much more important to learn quickly that the lead content of the blood is within a certain significant range of values than to learn much later the value correct to $0.001 \mathrm{mg}$. per $100 \mathrm{~g}$. of blood.

The advantages of the method to be described are : (1) The amount of blood required is only $0.5 \mathrm{ml}$., which can be obtained by finger prick. (2) No expensive apparatus is required. (3) All the manipulations are carried out in the one vessel. (4) A single determination can be done in two hours, or five in three hours with six flasks.

Briefly the method is to carry out wet oxidation of the organic matter in the blood, and then to determine the lead by the mixed-colour dithizone method.

Fischer $(1929,1934)$, and Fischer and Leopoldi (1934) have described very fully the properties of dithizone and of the compounds formed by it with a large number of metallic elements.

Many investigators have used dithizone for the determination of lead in biological and other materials, and the advantages of the mixed colour method for the determination of lead in various substances have been shown by Clifford and Wichmann (1936), Harrold, Meek, and Holden (1936), Hubbard (1937), Shiels (1938), and Bambach $(1939,1940)$. Nothing new is claimed in this method, except its application to determining lead in very small amounts of blood.

Spectrographic and polarographic methods for the determination of lead in a drop or so of blood have been described previously but the apparatus required is expensive, or not so suitable for the simultaneous determination of a number of samples. The present method requires a considerable amount of manipulative skill but no costly apparatus.

Principle of the Method

After the blood has been wet ashed to destroy organic matter and convert lead to

* Received for publication October 6, 1953 the ordinary ionic form, the lead is determined by titration using the mixed-colour dithizone method. Enough dithizone solution is added to the test to produce a mauve solution, i.e., one containing approximately equal amounts of dithizone (green) and lead dithizone (red).

Exactly the same volume of dithizone solution is added to the blank and sufficient lead is then added to this until a match is made with the test solution. The amount of lead added should then be equivalent to the amount of lead originally present in the test. It is important that the titration be done with a mauve solution as the endpoint, for with such a solution a more appreciable change is produced by one drop of lead standard than with a solution containing an excess of either dithizone or lead dithizone.

\section{Apparatus}

All glass apparatus is of "pyrex" glass. It must be cleaned thoroughly with nitric acid and rinsed well with distilled water before use. Water which has been double distilled in "pyrex quick-fit" apparatus or by an electric still has been found satisfactory.

Small Kjeldahl-like Flask.-This consists of an asymmetric bulb of volume $17 \mathrm{ml}$. with a long narrow neck $(9 \mathrm{~cm}$. long, $1 \mathrm{~cm}$. wide) fitted with a ground-glass stopper (Fig. 1).

Micro-Kjeldahl Rack.-This holds flasks at an angle of about $45^{\circ}$ and 1 in. above the flames of the microburners.

Graduated Pipette.-A $1 \mathrm{ml}$. graduated pipette has the tip drawn out to a very fine orifice and coated with paraffin which prevents the drops of lead standard solution from running back along the tip. Drops of volume $0.01 \mathrm{ml}$. can be delivered easily by this pipette.

\section{Reagents}

Lead Standard.--This is prepared from dry recrystallized lead nitrate. The standard solution is stored in paraffin-coated bottles and contains $1 \mathrm{mg}$. of lead per $\mathrm{ml}$. The dilute standard solution used in the titration $(0.005 \mathrm{mg}$. per ml.) is obtained by dilution of the stock solution and is freshly prepared each week.

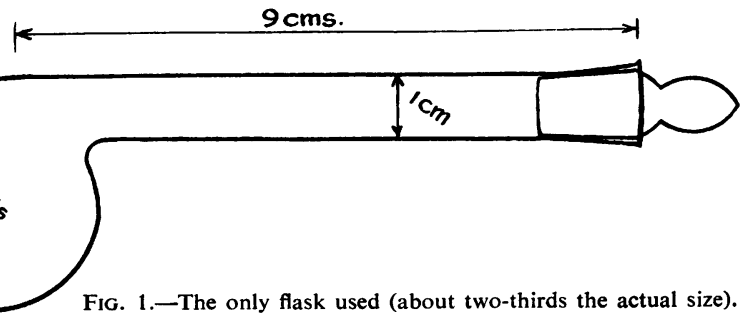


Dithizone Solutions.-Dilute solutions of dithizone in redistilled chloroform are freshly prepared each day. Two concentrations are suggested : Solution A, containing $0.5 \mathrm{mg}$. of dithizone per $100 \mathrm{ml}$. chloroform and solution B containing $0.25 \mathrm{mg}$. of dithizone per $100 \mathrm{ml}$. chloroform, but the concentration of dithizone solutions used are not critical as the same amount is always added to the test and to the blank. With experience, suitable concentrations of dithizone solution can be assessed by their appearance and it is then possible to prepare only the required amount (approximately $10 \mathrm{ml}$.) at a time.

Nitric Acid.-This is used redistilled in pyrex glass.

Nitrosyl-sulphuric Acid.-This is prepared by allowing redistilled nitric acid cooled in a freezing mixture to absorb sulphur dioxide which is passed into the acid for about three hours. This gives a solution of nitrosylsulphuric acid in sulphuric acid, which is used in order to obtain lead-free sulphuric acid by its decomposition.

Ammonium Citrate (30\%).-A few drops of ammonia are added until the $p \mathbf{H}$ is approximately 9 , and the solution is extracted with dilute dithizone until the chloroform layer is green. Excess dithizone is removed by shaking with redistilled chloroform.

Hydroxylamine Hydrochloride. - A saturated solution of reagent quality hydroxylamine hydrochloride is used.

Extractive Solution.-This is made up of $1 \%$ potassium cyanide and $1 \%$ ammonium citrate and purified from lead as is the ammonium citrate.

Ammonia.-Ammonia, $0 \cdot 880$, is heated and the evolved ammonia gas is collected in lead-free water, cooled in ice.

\section{Method}

Collection and Weighing of Blood.-The flask is cleaned thoroughly, drained and weighed. Sufficient blood is obtained by pricking a cleaned finger and allowing the drops of blood to fall down the neck of the flask ( 9 drops are approximately $\frac{1}{2}$ g.). The flask and blood are then weighed. Any blood which remains on the side of the neck is washed down by acid refluxing during the digestion.

Digestion.- The flask containing the blood and another cleaned flask (the blank) are then treated in exactly the same way as follows :-

Nitrosyl-sulphuric acid, $1 \mathrm{ml}$., is added and the flasks heated gently for about five minutes. The flasks' contents are then boiled steadily until white fumes of sulphur trioxide fill the flasks and the contents of the test flask have charred. Nitric acid is then added dropwise to the fuming solutions until the contents of the test flask are a pale yellow. If the solution is kept fuming while the nitric acid is being added the digestion can be completed in approximately one hour. The solution is cooled, and approximately $2 \mathrm{ml}$. of water added and boiled to expel any nitrogen dioxide fumes. The resulting solution is cooled. The final solution should be a very pale yellow.

Exactly the same amounts of the reagents are added to the blank as to the unknown.
Determination of Lead by Mixed-colour Dithizone Method.-The stoppers are placed in the flasks and the reagents, $1 \mathrm{ml}$. ammonium citrate and $1 \mathrm{ml}$. hydroxylamine hydrochloride, are added to both flasks, which are shaken after each addition. Sufficient ammonia is used to make $p \mathbf{H} 9 \cdot 0$. (Test with $p \mathrm{H}$ papers by inverting the flasks to wet the stopper, removing the stopper after reinverting, and placing it on the $p \mathrm{H}$ paper.) Then $1 \mathrm{ml}$. extractive solution and $1 \mathrm{ml}$. dithizone solution $\mathrm{B}$ are added.

The flasks are then thoroughly shaken and after checking the $p \mathrm{H}$, which should be the same in both the blank and the test, they are inverted so that the chloroform-dithizone layers can be compared. If the colour of this layer in the test ranges from blue to pinkish mauve no adjustment is necessary. However, if a pink is obtained, dithizone solution is added $\frac{1}{2} \mathrm{ml}$. at a time until sufficient excess of dithizone is present to produce a mauve, the same amount being always added to the blank. For the first $\frac{1}{2} \mathrm{ml}$. the dithizone concentration used is $0.25 \mathrm{mg}$. per $100 \mathrm{ml}$., but after this addition the most suitable concentration is $0.5 \mathrm{mg}$. per $100 \mathrm{ml}$. From the number of millilitres of dithizone solution required to obtain a mauve-coloured chloroform-dithizone layer in the test the approximate titration value can be gauged.

\begin{tabular}{c|c|c}
\hline $\begin{array}{c}\text { Vol. Dithizone } \\
\text { Solution }\end{array}$ & $\begin{array}{c}\text { Vol. of Lead } \\
\text { Standard } \\
\text { Producing Mauve } \\
(\mathrm{ml})\end{array}$ & $\begin{array}{c}\text { Vol. of Lead } \\
\text { Standard } \\
\text { Producing Pinkish } \\
\text { Mauve (ml.) }\end{array}$ \\
\hline $1 \mathrm{ml}$ solution A & 0.075 & 0.10 \\
$1 \frac{1}{2} \mathrm{ml}$ solution A & 0.125 & 0.15 \\
$+1 \frac{1}{2} \mathrm{ml}$. solution A & 0.20 & 0.25 \\
$+1 \frac{1}{2} \mathrm{ml}$ solution B & 0.30 & 0.35 \\
$+1 \mathrm{ml}$ solution A & 0.40 & 0.45 \\
\hline $1 \frac{1}{2} \mathrm{ml}$ ml. solution B & & \\
\hline
\end{tabular}

By adding dithizone solution in this way a suitable colour for comparison can be obtained for values of lead up to $0.45 \mathrm{ml}$. Lead standard (corresponding to a blood lead value of $0.00225 \mathrm{mg}$. per $\frac{1}{2} \mathrm{~g}$. of blood) and the maximum volume of dithizone solution used is $3 \mathrm{ml}$. For blood lead values greater than $0.45 \mathrm{mg}$. per $100 \mathrm{~g}$. (indicated by the formation of a red with very little shaking, after the addition of $2 \frac{1}{2} \mathrm{ml}$. dithizone solution) a stronger concentration than $\frac{1}{2} \mathrm{mg}$. $/ 100 \mathrm{ml}$. can be used for the last addition of $\frac{1}{2} \mathrm{ml}$.

When the colour of the chloroform-dithizone layer has been adjusted to a mauve, and the same amount of dithizone has been added to the blank, the titration is carried out.

Dilute lead solution is added to the blank from the graduated pipette and after each addition the flask is shaken thoroughly, inverted, and compared with the chloroform-dithizone layer in the test flask. When the colours of these layers match, the amount of lead added from the pipette equals the amount of lead in the weight of blood taken. When the end-point is near the lead solution is added one drop $(0.01 \mathrm{ml}$.) at a time. The final titration value is obtained in the following way: It may be found that addition of $0.10 \mathrm{ml}$. of lead solution 
produces a colour in the chloroform-dithizone layer which is slightly bluer than the colour of this layer in the test and that a further addition of $0.01 \mathrm{ml}$. produces a colour which is slightly pinker than the test. Hence, the titration value is between $0 \cdot 10$ and $0 \cdot 11$. It is then possible to judge between these two values depending on whether the colour of the test is nearer the colour produced in the blank by 0.10 or $0.11 \mathrm{ml}$. of standard solution, e.g., if it is exactly midway between the two, the titration value is taken as $\mathbf{0 \cdot 1 0 5}$.

If the amount of lead solution added to the blank at any time during the titration gives too great a colour change, then back titration can be carried out, that is, more lead can be added to the test until the colours match.

\section{Precautions}

Care must be taken to digest the sample completely. The colour of the aqueous layer during the final titration should be pale yellow.

The amount of dithizone used should be adjusted so that the colour being compared is mauve. If too much dithizone is present the pink of the lead-dithizone is obscured and the titration is not sensitive. If too little dithizone is present the colour is too pink and again a suitable match cannot be obtained. Possibly, the final colour to aim for may vary somewhat with different observers, but usually the mauve seems to be the most sensitive.

\section{Results}

The method was checked as follows :-

Known amounts of lead were added to normal blood by another analyst and the normal blood lead value was subtracted from the value obtained by titration of the reagent blank. It was, therefore, necessary to do a blood blank at the same time as each series of tests.

The results are summarized in the Table.

\section{Discussion}

It should be emphasized that in contrast to the procedure in other methods, in this method the whole of the procedure, including collection and weighing of blood, the wet oxidation, the addition of reagents, the extraction of lead dithizone into the chloroform layer and the final
TABLE

SUMMARY OF RESULTS

\begin{tabular}{|c|c|c|}
\hline $\begin{array}{l}\text { Amount of Lead } \\
\text { Added (mg./100 g. } \\
\text { blood) }\end{array}$ & $\begin{array}{c}\text { No. of } \\
\text { Determinations }\end{array}$ & $\begin{array}{c}\text { Recovery (\%) with } \\
\text { Standard Errors of } \\
\text { Means }\end{array}$ \\
\hline $\begin{array}{l}0.00-0.09 \\
0.10-0.19 \\
0.20 \text { and over }\end{array}$ & $\begin{array}{r}10 \\
10 \\
5\end{array}$ & $\begin{array}{c}111.6=9.95 \\
98.5=3.37 \\
97.95=2.03\end{array}$ \\
\hline $\begin{array}{l}\text { All values } \\
\text { Values } 0 \cdot 10 \text { and over }\end{array}$ & $\begin{array}{l}25 \\
15\end{array}$ & $\begin{aligned} 103.6 & =3.10 \\
98.6 & \pm 2.4\end{aligned}$ \\
\hline
\end{tabular}

matching are all done in the same vessel. This keeps the volume of reagents down to a minimum and avoids manipulative errors due to the use of separating funnels, transfer of solutions from one vessel to another, and washing out of vessels to secure last traces of transferred solution, filtering, and so on. When dealing with small amounts of lead these points are very important.

Bismuth or thallium, if present, would interfere. However, in the absence of bismuth medication the occurrence of this element in the blood is extremely rare. The presence of thallium is so rare that in ordinary practice it can be ignored.

\section{Summary}

A simple and inexpensive method for the determination of lead in small quantities of blood which can be obtained by a finger prick is described.

Five determinations can be done in three hours.

Results are quite accurate enough for clinical purposes, the average percentage recovery for all values (15) equal to or greater than $0 \cdot 10 \mathrm{mg} . / 100 \mathrm{~g}$. of blood being 98.64 \pm 2.4 and the average percentage recovery for all values (25) $103 \cdot 63 \pm 3 \cdot 10$.

\section{REFERENCES}

Bambach, K. (1939). Industr. Engng Chem. (Anal.), 11, 400. - (1940). Ibid., 12, 63.

Clifford, P. A., and Wichmann, H. J. (1936). J. Ass. off. agric. Chem., Wash., 19, 130.

Fischer, H. (1929). Z. Angew. Chem., 42, 1025.

Fischer, H. (1929). Z. Angen

- (1934). Ibid., 47, 685.

Harrold, G. C., Meek, S. F., and Holden, F. R. (1936). J. industr. Hyg., 18, 724 .

Hubbard, D. M. (1937). Industr. Engng Chem. (Anal.), 9, 493. Shiels, D. O. (1938). J. industr. Hyg., 20, 581 . 